\title{
VARIABILITY OF BOUNDARY AND MEANING OF DIVERSITY ATTRIBUTES: STUDIES FROM DIVERSITY MANAGEMENT AT A JAPANESE SME
}

\author{
NORIKO YAGI \\ SEIGAKUIN UNIVERSITY
}

\begin{abstract}
Drawing on a case of diversity management in small and medium-sized Japanese enterprises (SME), this paper argues that an anthropological approach can contribute more to progress our understanding about the effect of diverse people working together in naturally occurring work groups. The paper reveals a more nuanced and fluid nature of the boundary of diversity attributes and meaning that people associate with them-such a perspective is not attainable through quantitative methodology which is widely used in current diversity management research in management science. The anthropological approach adds rich details that give the quantitative data depth and meaning in the real world.
\end{abstract}

Keywords: diversity management, anthropological approach, Japanese SME

\section{Introduction}

Diversity management is one of the recent buzzwords in Japan. The Ministry of Economy, Trade and Industry (METI) has selected and awarded 100 Best Practices of Diversity Management Strategies annually since 2013 (Keizai Sangyosho, 2015). A couple of factors influenced this trend. First, the Japanese economy has been stagnating for two decades: "Lost two decades" is a spell that has bound the nation. Another factor that currently and will bind the future of the nation is the double jeopardy of an aging society and a declining birth-rate. A consequent labour shortage will fundamentally damage the nation's growth potential. It is hoped that diversifying the nation's workforce will be a panacea for the situation. 
METI claims that promotion of diversity management is a must for Japan because it will facilitate change in the nation's economy to a "kachi sozo [value creation]" economy and, in turn, enable the economy to continuous grow. These claims are in line with the expectations of diversity management, often called the "business case" for diversity (Qirko, 2012). The business case for diversity is that a diverse workforce will bring about positive outcomes, such as: the competitive advantage of attracting and retaining the best talent drawn from a diverse pool of workers; creative synergy and consequent organizational productivity; and a fuller understanding of an increasingly diverse marketplace (Kochan et al., 2003; Konrad, 2003; Lattimer, 1998).

For most of Japan's SMEs, however, seeking positive outcomes is hardly a primary reason to engage in diversity management, but coping with the imminent crisis they face-labour shortages - forces SMEs get involved in it. According to a survey of SMEs in Japan, about 40 per cent of respondents answered that the labour shortage affects their business in a way that makes it difficult to maintain the current scale of business; technology and know-how will be difficult to advance; and they cannot respond to an increase in demand, thus suffering opportunities (Mizuho Joho Soken, 2017). Despite the call by the METI and other governmental agencies, Japanese companies still want to hire a conventional workforce - newly-graduated Japanese, mainly male, if it is attainable. Put another way, a homogeneous workforce is preferred. For SMEs, this demographic is hard to recruit. SMEs seeking an instant remedy to the labour shortages tend to tap into two diverse groups, women and foreigners. As a result, Japan's SMEs have been forced to tackle diversity management.

This paper examines just such "unintended" diversity management that Japan's SMEs are now experiencing. A SME located in the Tokyo suburbs, Kanto Foods (not its real name), is one company in which the author has conducted fieldwork. The anthropological fieldwork reveals a fresh perspective on the nature of diversity attributes that is not elaborated in the management science research on diversity management. Diversity management research in management science has studied how group composition affects group performance, cohesion, and social interaction, and group members' commitment, satisfaction, and other indicators of subjective well-being (van Knippenberg \& Schippers, 2007). Their emphasis is placed on either the preference for working with similar types, or the value of diverse information, knowledge and perceptions. An unspoken assumption held by this stream of research is that they attach only one meaning to diversity attributes - difference. Regardless of which diversity 
attribute they treat, such as gender, age, ethnicity, tenure, educational background, or functional background, the meaning that the researchers associate with the attributes is the same: are they different (or similar)? In the quantitative methodology that most management science research utilizes, diversity attributes are treated as a variable, often an independent variable. It must have a clear boundary that differentiates one variable from another in order to measure them accurately (Judd, Smith, \& Kidder, 1991).

This paper argues that the meaning that local people associate with diversity attributes can change, shift, or even evolve. Different or similar is not the only meaning they come up with when they encounter diverse workers in a workplace. The qualitative nature of the anthropological approach primarily studies the subject "from the ground up". This enables the meaning as experienced by participants in a given setting, rather than on the basis of the attribute characteristics set by the researchers, to be captured.

In the next section, the paper starts by introducing the typology of diversity attributes in the management science literature. The refinement of typologies exemplifies the efforts of management science to cope with inconsistent results gained through empirical studies of diversity management. Next, the paper introduces readers to Kanto Foods. The shifting meaning and fluidity of the boundary of diversity attributes are examined through the findings from the fieldwork. Then, the paper concludes by discussing the contributions that business anthropology can make to advance our understanding of diversity management.

\section{Typologies of Diversity in Management Science}

In the management science literature, diversity is more narrowly defined than its usage in everyday conversations. Diversity describes the extent to which members of social units (e.g. work teams) are dissimilar from each other on one or more attributes (Jackson \& Joshi, 2011). To better understand how diversity influences work teams, a number of researchers have proposed typologies to classify different dimensions of diversity.

These typologies include differentiating between relations-oriented and task-oriented diversity (Jackson, May, \& Whitney, 1995; Milliken \& Martins, 1996). Relations-oriented diversity refers to the distribution of attributes that are instrumental in shaping interpersonal relationships, but which typically have no apparent direct implications for task performance. Age, gender, and personality characteristics are examples of relations-oriented 
diversity. Task-oriented diversity refers to the distribution of attributes that are potentially relevant to the team's work. Organizational tenure, formal credentials and titles, and cognitive abilities are examples of task-oriented diversity.

The other way is to differentiate the diversity attributes between readily detected (or surface-level) diversity and underlying or deep-level diversity. Readily detected diversity refers to differences among team members on attributes such as gender, age and nationality. Those attributes are easily discerned or quickly discovered. Underlying diversity refers to differences among team members on attributes that generally become known only through interaction, such as personality, attitudes, and skills.

One underlying assumption about these typologies is that different types of diversity may have different consequences for work teams. For example, some researchers have proposed that demographic diversity, much of which is situated on a cross section of relations-oriented and readily detected attributes, has negative effects on group performance and affective-evaluative responses to the group (Jehn, Northcraft, \& Neale, 1999; Pelled, Eisenhardt, \& Xin, 1999). On the other hand, diversity of task-oriented attributes, such as education and functional background is expected to have positive effects on group performance (Finkelstein \& Hambrick, 1996; Jehn \& Mannix, 2001).

Harrison and Klein (2007) propose yet another approach to redress this confusing state. They suggest that the very construct of diversity requires closer examination and refinement - diversity is not one thing but three things. They propose that diversity within an organization unit may be indicative of either "separation", "variety", or "disparity". Separation means differences in position or opinion among unit members. Such differences reflect disagreement or opposition - the horizontal distance along a single continuum representing dissimilarity in a particular attitude or value. Variety indicates differences in kind or category, primarily of information, knowledge, or experience among unit members. Finally, disparity means differences in concentration of valued social assets or resources such as pay and status among unit members-vertical differences that, at their extreme, privilege a few over many. They argue that diversity's substance, pattern, operationalization, and likely consequences of those three things differ markedly.

In opposition to these assumptions, some researchers started questioning the effectiveness of these typologies. Based on a review of meta-analysis studies, van Knippenberg and Schippers (2007) conclude that the distinction between diversity types is not associated with differential relationships with outcome variables. 
These efforts to refine the typology of diversity attributes can be understood as an attempt to break through an impasse of diversity management research. Jackson and Joshi (2011) point out the complexity found in naturally occurring work teams, combined with overly simplistic approaches to measuring team diversity, makes it impossible to draw conclusions about whether the different types of diversity attributes are associated with differing team consequences. They encourage management science scholars to be vigilant about measuring, evaluating, and reporting the effects of as many types of diversity as is feasible when conducting their research. Anthropological fieldwork is ideal for investigating the complexity found in naturally occurring work teams.

In the next section, the paper introduces Kanto Foods, where the complexity of interaction of a diverse workforce was investigated.

\section{Field Study}

\section{Outline of Kanto Foods}

Kanto Foods forms a link in the restaurant-industry supply chain - it processes vegetables into a ready-to-use form and sells to contracted restaurants and take-away lunch companies. Their business has grown steadily over the past twenty years because of a strong demand for their products. More Japanese consumers dine out, and fewer cook at home. The industry association estimated the size of the Japanese restaurant industry as JYE25, 417 billion (USD227billiion) in 2016 (Nihon Hudo Sabisu Kyokai, 2017). In line with industry growth, Kanto Foods, which started as a famer's side business now employs about 140 people.

The current top management team, which consists of a president and a managing director, is from the third generation of the founding family. Mr. Kubota (all names appearing in this paper are pseudonyms), the managing director, told me that while he saw an opportunity for their business to grow further, he felt that they were being hampered by shortage of labour. He said, "It is not surprising that we do not receive any applications from our local newspaper advertisements." The difficulty in recruiting employees comes from people's perception of their working environment, Mr. Kubota explained. He said that, "Our factory is seen as a $3 \mathrm{~K}$ workplace by many Japanese people, especially young ones, such as high school graduates and university graduates." Three Ks stand for kitsui (difficult or tough), kitanai (dirty), kiken (dangerous) that symbolize an undesirable workplace for job seekers. 


\section{Ks at Kanto Foods}

A factory tour that I was given showed the working environment. Before entering the shop floor, I first needed to don a white coat, a pair of white rubber boots, a white surgical mask, and a white net cap. After changing clothes, I was told that the shoulder and back of the white coat must be cleaned for 30 seconds with a roller with adhesive tape: a kitchen timer was placed on a cabinet for this purpose. Next, you look in a mirror and check whether there are any stray hairs. Before going through a plastic curtain to the shop floor, you must soak the boots in a tub of chlorine water for 30 seconds. All this is needed to ensure the cleanness of their products. For instance, a strand of hair found in an item could ruin the entire business. In this respect, their workplace is the opposite of kitanai (dirty). They have to ensure cleanness for the survival of their business, although ironically, the pursuit of cleanliness resulted in making the working environment kitsui (difficult or tough) and kiken (dangerous).

When I was finally allowed to enter the shop floor, it was cold. It must be cold to keep the vegetables fresh and crisp. The air on the floor was a mix of chopped vegetables and chlorine. White boards were placed to show the day's order from the clients-30 bags of onions, chopped for Client X, 5 kilograms of cabbage, shredded for Client $Y$, and so on. Boxes of vegetables that were unloaded from trucks were brought into an inspection area by forklifts. After the inspection, vegetables were washed and machine-cut into a manageable size. Then they were sorted out according to the orders and carried into a room with working tables. One working table is shared by four persons. At the table, workers hand-cut vegetables with kitchen knives. I asked a factory manager why all the procedures cannot be mechanized, why human beings need to cut the vegetables by hand-it looks not only dangerous but also inefficient. The answer was because a portion of each order is small, and the specifications vary from one client to another, thus mechanization is difficult. Workers chop carrots into 1-centimeter dice for Client $\mathrm{X}$ and 5-millimeter dice for Client Y. Once vegetables were processed, they were packed immediately or they were soaked into a pool of chlorine water to sanitize before packaging, depending on kind and method of preparation. Workers are on their feet in a cold and humid room for three to four hours, till break time.

The other difficulty involves the work schedule that Kanto Foods needs to abide by. The restaurant industry in Japan never sleeps. In order to meet the demand, there is a night shift. During the year-end and New Year's three-day period, when most Japanese people take a break, staff at Kanto Foods must keep on working. Convenience stores are open seven days a week and sell lunch boxes and other ready-to-eat side dishes. Then, 
someone must supply the ingredients to the food factories - those are the people working at Kanto Foods.

Top management said that they had tried hard to recruit full-time employees, but they have to rely on the part-timers and foreign workers - a major reason for the difficulty in hiring is because the working conditions, they interpreted.

\section{Diversity from Top Management's Point of View}

The fieldwork from which this paper draws was initially planned as a study of the organizational culture of Kanto Foods and its diverse workforce. The fieldwork was to search for shared understandings at Kanto Foods that workers and top management co-created there. For that purpose, I was allowed to interview rank-and-file workers, both part-timers and full-time workers. Seventeen semi-structured interviews were conducted. Among them, ten were Filipinos, five were Japanese, one was Brazilian, and one Chinese. In addition, I had a series of conversations with a Japanese manager of general affairs who arranged the interview schedule for me.

Although the initial purpose of the study was organizational culture at large, through the first series of interviews it became apparent that the meaning of "diverse" workforce differed substantially among the members of Kanto Foods. Top management's perception of the diverse workforce was seen from the way they explained the composition of employees to me at the initial interview. "We have about 140 employees in total. Foreign workers are about 50-60 persons. Among the Japanese members, about 70 are part-timers and 22 are full-time workers." In this statement, diversity attributes they recognized are: nationality (foreign versus Japanese) and employment status (part-time versus full-time). Eventually, gender is found to be another key attribute. Almost all the part-timers were Japanese housewives, whereas full-time workers were Japanese males.

Among these attributes, nationality (foreign versus Japanese) was fore-grounded by top management. In the same interview, the top management raised concerns about a safety issue, in that foreign workers did not follow the company's safety instructions. Mr. Kubota brought a stack of papers with him. They were print-outs of safety signage in English. He told me that he was wondering if it would be useful to post these English instructions in the factory to improve the level of cognition of foreign workers to the safety instructions. This act indicates that a diversity attribute of foreignness is associated with a difference of language. The difference of language, in turn, brings about insufficient 
communication that potentially risks the organization's performance. This is a line of thought that guides the diversity management conceived of by top management.

An interesting twist was that while top management was interested in posting English-language signage in the factory, they did not talk about the nationalities of their non-Japanese staff. Did any of them understand English? Mr. Kubota came up with the name of one Filipino, David, who was fluent in English and top management hoped he could be a group leader of the foreign workers. In fact, the Filipinos were the biggest group in terms of nationality among foreign workers. Fewer Chinese people were interested in working for a company like Kanto Foods, nowadays, Mr. Kubota said, as the nation's economy has developed.

\section{Diversity Experienced by Shop Floor Workers}

While the nationality attribute was the most salient for top management, it was not so for the Japanese part-time workers. Attributes that were foregrounded by them were organizational tenure and employment status.

Most of the part-time workers were Japanese housewives, and sensitive about organizational tenure. In all the interviews, I asked first how long they had worked for the company. This question elicited a reaction among Japanese part-timers to recall the very first days when they joined the company. Many mentioned how nervous they were in front of the long-time workers. The long-timers knew how to get the job done-how to read the order sheet, the way to cut vegetables, and where to carry the final products out for shipment, etc. In other words, the long-timers set the workplace tone. Those long-timers were not necessarily full-time workers. Rather, they were often part-time housewives who taught newcomers. One part-timer recalled that "I was careful not to be scolded by some part-timers who have been here for a while."

Employment status was found to be one of the most important attributes shared among the Japanese part-timers as well. On the shop floor, the person's identity was hard to recognize because everyone wore a white coat and a surgical mask. It was the colour of the cap that showed their employment status clearly - a white cap indicates part-timers; a green cap indicates "haken shain," temporary staff members dispatched from agencies - all of them are foreign workers; and then a blue cap indicates full-time employees. This identification system was introduced in order to help part-timers and temporary staff members so that they could easily find the full-time workers if they needed information. The questions about how to get the job done, however, were dealt with by the part-time 
workers who have a long tenure. Instead of calling out to a full-time worker who is working far away, it is more convenient and helpful to ask a long-timer standing nearby.

Long-timers not only field questions but also monitor their colleagues' behaviour if they deviate from safety procedures. Mrs. Taira, who was one of the longest in tenure, said, "I don't mind telling them the things like, 'Put your cap straight' or 'Did you soak your boots?' because it is important for me that our company does well. In fact, that should the full-time workers' job. I think they are too lenient. They should be more stern and should say 'It is wrong,' if someone made a mistake." Mrs. Taira, as a part-time worker, was dissatisfied by the work attitude of full-time workers. A situation like this brought employment status to the fore among other diversity attributes. Part-timers saw that full-time workers were privileged in terms of employment conditions. The work of full-timers, however, did not match up to the privileges they were awarded, the part-timers believed.

When it comes to the nationality attribute, the perception of Japanese housewives toward foreigners is more nuanced than that of top management. As I interviewed part-time Japanese housewives, they seldom talked about "foreign" colleagues unless I asked about them. Rather, their talk touched more on the organizational tenure and employment status. When I asked about foreigners, then, Mrs. Takeda who had worked here for five years said, "Oh yes, I was surprised at first because it was the first time I had seen foreigners. I felt scared of them. I thought that this company is hiring a lot of foreigners. But now I've got used to it." When I asked how they communicated with foreigners, they admitted that foreigners hardly spoke Japanese. However, it does not matter very much, they said. By showing how to do it, then they can communicate with each other. Thus, the language, which the top management associated with the nationality attribute, did not really bother the Japanese part-timers. They were relatively indifferent to the issue of language of foreign workers.

Rather, it was a certain type of behaviour of foreign workers that attracted the Japanese housewives' attention. Mrs. Isoda who had worked for seven years, mentioned her experience when she was dragging a container filled with heavy vegetables, such as pumpkins, potatoes, and onions. One Filipino guy came by and carried the container on behalf of her. Said she, "People from the Philippines are kind, I thought." She said that male Japanese workers seldom gave such a helping hand to female workers. From the Filipino man's perspective, he may act in accordance with the cultural norm in the Philippines - a kind of chivalry spirit 
expected of Filipino men to show towards a woman in trouble. The act may not have stood out in the Filipino cultural context, but in the Japanese $3 \mathrm{~K}$ work context the act was interpreted as carrying a special meaning, that is, "kindness."

A language difference that was tied to the diversity attribute of nationality by the top management, showed a different picture when it was seen from the foreign workers' perspective. Diversity of nationality, by definition, draws a line along the boundary of nations. It is natural for the Japanese to think that the boundary of nation and the boundary of language overlap. For the Filipino workers, however, the language boundaries run through the nation. As previously depicted, top management expected David to be a leader of foreign workers. The top management, and were puzzled when he was reluctant to assume the leadership role. I asked him if he knew that top management wanted him to be a leader. He said that he did know it. He did not want to take the offer because there was no point in accepting such a difficult task, since it was not an official position, and carried no extra pay. And also, diversity among the Filipino workers emerged as a reason for David's reluctance to be a leader. He was from the Manila metropolitan area, whereas many other Filipinos came from the region where Visayan was the native language. In addition, David was a university graduate, but most of the other Filipinos were only high school graduates. His educational background and the region of origin within the nation gave him proficient English. On the other hand, he did not feel that he belonged to the community to which other Filipino workers there belonged.

\section{Variability of Boundary and Meaning of Diversity Attributes}

Comparison between top management and shop floor workers in terms of their perception of diversity at Kanto Foods provides a point of departure for the analysis. Variability of diversity attributes has surfaced as an analytical perspective to better understand the complexity of diversity management in the naturally occurring work teams. Variability of diversity attributes is analyzed in two dimensions: boundary and meaning.

\section{Rigidity and Fluidity of Boundaries}

The nationality attribute that differentiates foreigners and Japanese is a case in point for discussing the variability of boundary. Rigidity of the boundary is found in top management, who single out foreign workers as 
one diversity group. A boundary is rigid when the boundary drawn around the diversity attribute hardly moves. A consequence of a rigid boundary is that once a person is compartmentalized, then that person is seen as a member of that compartmentalized group for the rest of the time.

In the case of top management, a language difference, one of the readily detectable characteristics, is bound tightly to the diversity attribute of nationality. Rigidity is shown because it stays unchanged even after top management encounter an incident that disproves the adequacy of boundary drawing. For example, when the top management came up with the idea of posting English-language signage to thoroughly enforce safety procedures, they knew that not all the foreign workers spoke English. Foreign workers are also not one group, but at least two - English speaking foreigners, and non-English speakers. This was an opportunity for them to realize that the boundary of nationality attribute could be more fluid. Nevertheless, the boundary remains unchanged for the top management. Foreign workers are continued to be perceived as one diversity group.

The shop floor workers' take on the nationality attribute marks a contrast to that of top management's. A characteristic such as the language difference is detectable for the shop floor workers as well. Yet, such detectable characteristics wane eventually as the interaction among a diverse workforce increases. Few Japanese part-timers mentioned the presence of "foreign" workers until I directly asked them. Proficiency of Japanese does not matter very much for a shop floor job, both foreign workers and Japanese part-timers observe. Mrs. Takeda's concise response to my question exemplifies it. Such a perception cuts across the boundary of nationality diversity attribute. Foreign workers and Japanese part-timers are united under the boundary of employment status as non full-time workers. When a boundary is more fluid, people compartmentalized within the boundary can cross the boundary easily-sometimes they are seen as an outsider, and at other times are seen as being inside the boundary, as the boundary changes.

\section{Fixed Meaning and Shift of Meaning}

The meaning that people associate with the diversity attribute is analyzed separately from the variability of boundary. Meaning might shift as a boundary moves; at other times, meaning might be fixed even when a boundary has moved.

A shift of meaning denotes a change of meaning associated with a certain diversity attribute. This is observed in the interaction among the shop floor workers. The nationality diversity attribute distinguishes 
foreign workers and Japanese workers. Mrs. Takeda mentioned that she was initially scared of foreigners. A sense of fear was associated with foreigners constitutes the meaning of nationality diversity attribute. This meaning is bound to detectable characteristics that foreigners stand out because of their "foreignness". The prominence of foreignness, however, decreases as the interaction among a diverse workforce increases. But not only do the detectable characteristics wane, but a new interpretation of the diversity attribute also emerges with over time. For instance, consider the Filipino male worker who helped to carry a heavy container of vegetables for the Japanese female worker. Such a social act triggers the creation of a new meaning towards the diversity attribute. The meaning of the nationality attribute shifted from the fear that comes from mere distinctiveness to a more nuanced one aligned with cultural characteristics, such as spontaneous kindness extended to female workers.

In contrast, meaning was fixed for the top management with regard to the nationality diversity attribute. The language difference that is bound to the attribute anchors the meaning of inability to communicate in Japanese. A connection is found that the fixed meaning relates to the rigidity of boundary. Rigidity of boundary is seen when foreign workers are perceived as one diversity group regardless of their nationality or whether they speak English or not. Thus, when the boundary of diversity attribute is rigid, the meaning associated with the attribute tends to be fixed.

\section{Triggers for Variability}

Findings from the fieldwork also suggest the triggers for variability. As we have seen, a degree of variability of diversity attributes differs from one group to another. One of the triggers that change the variability of boundary (either rigid or fluid) would be a distance from the site in which people interact with each other.

Rigidity of boundary is a pronounced characteristic of the quantitative approach towards the research. Their approach to examining the causal relationship between the variables necessitates defining the boundary of variables, because all the variables need to be "measured". The top management's rigid view of the boundary of diversity attributes infers that they tried a similar as approach to the quantitative researchers'. A distance from the subject, in this case the shop floor workers, is the commonality that is shared by the top management and the quantitative researchers. The top management of the company are distant from the shop floor by means of the organizational hierarchy, whereas the quantitative researchers maintain a distance from the subject for the sake of "objectivity". 
The shop floor workers are the actors of interaction, which means no distance exists between the actors and their act. Under such a condition, the boundary of diversity attributes becomes fluid and the meaning people associate with the attributes can shift and change. This fluidity poses a "problem" for the quantitative researchers, for it makes it difficult to "measure" the variables. But for the qualitative researchers, it is the wealth from which we can tease out the richer meanings that the local people create in their everyday lives.

Another trigger of variability in diversity attributes is the presence of an overarching attribute. According to the shop floor workers' experience, diversity attributes form a multilayer structure. Organizational tenure and employment status emerged as an overarching diversity attribute that is salient to both Japanese part-timers and foreign contracted temporary workers. The nationality diversity attribute can be situated under these overarching attributes. The presence of overarching diversity attributes, in turn, dissolves the boundary of the lower layer attribute, such as nationality.

In sum, the field study found triggers that change a degree of variability of diversity attributes. A distance from the place where the interaction occurred is a key trigger that influences variability. The boundary of the diversity attribute becomes rigid when the perceiver is more distant from the place. The boundary is more fluid when the perceiver is on a locus of interaction. The meaning that people associate with the diversity attributes is also variable. A change in meaning is more likely to occur when people have opportunities to interact with each other over the boundaries of diversity attributes. The shop floor workers are active participants in the interaction, whereas top management are passive bystanders.

\section{Conclusion}

Qirko (2012) argues that anthropological method and theory are consistent with the goals of diversity management, and the opportunity for applied anthropologists to contribute to this field seemed ideal. This call is particularly relevant for the Japan's SMEs today that are inadvertently forced to cope with the diversity management. Many of the top management of SMEs have to start managing a diverse workforce without much knowledge about group(s) of the people newly entering their companies-they are like anthropologists entering a field where not only do they not speak the language, but also do not know the rules of acceptable behaviour. Utilizing the qualitative technique would therefore be beneficial to an SME's top management to explore the cultures that 
newcomers bring into the organization. Jordan (2010) mentioned that anthropologists have worked as culture brokers and helped assist multinational corporations understand the cultures of the many countries in which they operate. Nowadays, it is not only the big multinationals, but also SMEs that need culture brokers who can help cultural groupings understand each other. Anthropologists, who have been trained to look with fresh eyes, and make no assumptions about understanding things, do help business practitioners to better understand the multiple cultures incorporated into their organization.

My fieldwork at Kanto Foods showcases that qualitative data adds the rich details that enable our understanding of meaning in the real world. Top management struggled to understand the cultural meaning of newcomers. After all, they ended up relying on the diversity attribute of nationality in a way that Qirko (2012) called a "pre-coding trend". Clients and/or participants in a given cultural setting pre-select categories, such as race and gender, under the assumption that these will be the most relevant dimensions to an audit. However, top management's distance from the site of interaction - the shop floor, e.g . - hinders an accurate interpretation the meaning of the diversity attributes consistent with the interpretation by rank-and-file workers.

As Jayne and Dipboye find in their review of research on effective diversity management, "A thorough needs-assessment of the people, jobs, and organization ensures that issues related to diversity are framed accurately and that the right interventions are identified" (2004: 416). Anthropologists are therefore particularly qualified to assist in managing diversity efforts, given their understanding of the acquisition and transmission of culture, cultural variability and change, and sub-cultural and multicultural relationships (Jordan, 2010).

Business-related diversity issues are clearly here to stay. Not just in Japan, but everywhere in the world, the increasing number and variety of demographic and cultural factors characterizes the change of human resources upon which companies count. Then, more nuanced views of diversity attributes identified through anthropological methods, contribute to our understanding of the effects of diverse people working together in naturally occurring work groups. 


\section{References}

Finkelstein, S., \& Hambrick, D. C. (1996). Strategic leadership: Top executives and their effects on organizations. Minneapolis/St Paul: West Publishing.

Harrison, D.A., \& Klein, K.J. (2007). What's the difference? Diversity constructs as separation, variety, or disparity in organizations. Academy of Management Review, 32(4), 1199-1228.

Jackson, S.E., \& Joshi, A. (2011). Work team diversity. In S. Zedeck (Ed.), APA Handbook of Industrial and Organizational Psychology (Vol. 1, pp. 651-686). Washington, D.C.: American Psychological Association.

Jackson, S.E., May, K.E., \& Whitney, K. (1995). Understanding the dynamics of diversity in decision-making teams. In R.A. Guzzo, E. Salas, \& Associates (eds.), Team effectiveness and decision making in organizations (pp. 204-261). San Francisco: Jossey-Bass.

Jayne, M.E.A., \& Dipboye, R.L. (2004). Leveraging diversity to improve business performance: Research findings and recommendations for organizations. Human Resource Management, 43(4), 409-424.

Jehn, K.A., \& Mannix, E.A. (2001). The Dynamic Nature of Conflict: A Longitudinal Study of Intragroup Conflict and Group Performance. Academy of Management Journal, 44(2), 238-251.

Jehn, K.A., Northcraft, G.B., \& Neale, M.A. (1999). Why differences make a difference: A field study of diversity, conflict, and performance in workgroups. Administrative Science Quarterly, 44, 741-763.

Jordan, A.T. (2010). The importance of business anthropology: Its unique contributions. International Journal of Business Anthropology, 1(1), $15-25$.

Judd, C.M., Smith, E.R., \& Kidder, L.H. (1991). Research methods in social relations (6th ed.). Fort Worth, TX: Harcourt Brace.

Keizai Sangyosho (Ministry of Economy, Trade and Industry) (Ed.) (2015). Keizai Sangyosho Heisei 26-nendo Daibashiti Keiei Kigyo 100-sen: Daibashiti Keiei Senryaku 3 (METI Selected 100 Companies of Diversity Management in 2014: Daiversity Management Strategies 3) Tokyo: Keizai Sangyo Chosa-kai.

Kochan, T., Bezrukova, K., Ely, R., Jackson, S., Joshi, A., Jehn, K., Thomas, D. (2003). The effects of diversity on business performance: Report of the diversity research network. Human Resource Management, 42(1), $3-21$.

Konrad, A.M. (2003). Defining the domain of workplace diversity scholarship. Group \& Organizational Management, 28(1), 4-17.

Lattimer, R. L. (1998). The case for diversity in global business, and the 
impact of diversity on team performance. Competitiveness Review, 8, 3-17.

Milliken, F.J., \& Martins, L.L. (1996). Searching for common threads: Understanding the multiple effects of diversity in organizational groups. Academy of Management Review, 21, 402-433.

Mizuho Joho Soken (2017). Heisei 28-nendo Chusho Kigyo Shokibo Jigyosha no Jinzai Kakuho Teichaku-tou ni kansuru Chosa Sagyo Hokokusho (2016 Survey work report on securing and fixing of human resources of SMEs and small-scale enterprizes). Retrieved from http://www.meti.go.jp/meti lib/report/H28FY/ 000222.pdf.

Nihon Hudo Sabisu Kyokai (Japan Food Service Association) (2017). Heisei 28-nen Gaishoku Sangyo Shijo Kibo Suikei ni tsuite (About estimation of market size for the food service industry in 2016). Retrieved from http://anan-zaidan.or.jp/data/2017-1-1.pdf.

Pelled, L.H., Eisenhardt, K.M., \& Xin, K.R. (1999). Exploring the black box: An analysis of work group diversity, conflict, and performance. Administrative Science Quarterly, 44(1), 1-28.

Qirko, H. N. (2012). Applied anthrpology and business diversity management. International Journal of Business Anthropology, 3(2), $107-129$.

van Knippenberg, D., \& Schippers, M. C. (2007). Work group diversity. Annual Review of Psychology, 58, 515-541. 